Acute lymphoblastic leukemia is the most common type of childhood cancer, accounting for about $23 \%$ of all cancers diagnosed in this age group. The last stage of radical treatment is remission maintenance, during which hospitalization is not necessary. The lesions occurring in the oral cavity caused by medications and chemotherapy may also be directly related to hematological and systemic disorders. The aim of this study was to examine the levels of selected pro- and anti-inflammatory cytokines in saliva and serum of both patients undergoing remission maintenance and those after the cessation of therapy who reported to the hematology clinic of the Pediatric University Hospital in Lublin. The results were later analyzed in relation to the frequency of oral lesions and subjective intensity of oral complaints. The study revealed significant differences in salivary and serum concentrations of TNF- $\alpha$ and IL-10 between test and control groups. Oral lesions were more frequent in patients receiving therapy compared to the control group. Subjective afflictions described by the Visual Analog Scale (VAS) mean values were highest in the control group.

Key words: acute lymphoblastic leukemia, cytokines, oral lesions.

Contemp Oncol (Pozn) 2019; 23 (2): 81-86 DOI:https://doi.org/10.5114/wo.2019.85878

\section{Salivary and serum concentrations of selected pro- and antiinflammatory cytokines in relation to oral lesions among children undergoing maintenance therapy of acute lymphoblastic leukemia}

\author{
Przemysław M. Krzaczek ${ }^{1}$, Małgorzata Mitura-Lesiuk², Joanna Zawitkowska², \\ Beata Petkowicz ${ }^{1}$, Barbara Wilczyńska ${ }^{3}$, Katarzyna Drabko² \\ ${ }^{1}$ Department of Oral Medicine, Medical University of Lublin, Poland \\ 2Department of Hematology, Oncology and Pediatric Transplantology, II Chair \\ of Pediatrics, Medical University of Lublin, Poland \\ ${ }^{3}$ Clinic of Pediatric Endocrinology and Diabetology with Endocrinological and Metabolic \\ Laboratory, III Chair of Pediatrics, Medical University of Lublin, Poland
}

\section{Introduction}

Acute lymphoblastic leukemia (ALL), constituting approximately $23 \%$ of all cancers diagnosed in childhood, is the most common oncological medical condition in this age group. $75 \%$ of children diagnosed with leukemia have this form of the disease. The incidence rate ranges from 30 to 40 cases/ 1 million children a year (in Poland this rate is 35.4/1 million). The highest incidence of illness is between 2 and 4 years of age and is 10 times higher than the morbidity at the age of 19 [1]. The etiology of ALL has not been fully understood yet. Neoplastic transformation can occur at any stage of differentiation of successive stages of the normal lymphoid line. Unrestrained proliferation of myeloid leukemic cells causes displacement of normal hematopoietic cells and lymphoblasts' infiltration to the lymph nodes, spleen, liver and other organs [2].

The therapeutic treatment is of a radical nature and its goal is a full recovery. The ALL therapy protocols feature the use of intensive polychemotherapy and typically include 4 phases. The first phase is the induction of remission with the intention of initially reducing the tumor mass and preventing the onset of tumor lysis syndrome. The next stage is prevention or treatment of the central nervous system infiltration. Remission consolidation follows and is aimed at eliminating residual leukemic cells. Each of the above-mentioned phases lasts about 2 months. The fourth stage is the maintenance of remission, during which hospitalization is not necessary. Maintenance treatment takes about 54 weeks.

Medications used in the ALL treatment protocol include 6-mercaptopurine, methotrexate, prednisone, vincristine, daunorubicin, L-asparaginase, cyclophosphamide and cytosine arabinoside. These drugs have high mucotoxicity. The 5-year survival rate among children with ALL reaches 82\% [3].

One of the most characteristic side effects of chemotherapy is oral mucositis. It occurs in approximately $40 \%$ of patients undergoing conventional chemotherapy and in over $70 \%$ of patients subjected to conditioning prior to bone marrow transplant. Among the transcription agents activated by free radicals, NF- $\mathrm{KB}$ appears to be responsible for the upregulation of certain genes leading to the excessive production of proinflammatory cytokines such as TNF- $\alpha$ and interleukin 6 (IL-6). The presence of these cytokines leads to accelerated apoptosis and tissue injury. The resulting clinical manifestation in the patient's mouth is acute inflammation followed by ulcerations 
accompanied by severe pain. The healing process of such lesions leaves scar tissue, keratinization disturbances in the squamous epithelium or mucosal atrophy [4].

The period of cytokines' biological activity in blood and body fluids is short. During the development of neoplastic diseases there is increased, uncontrolled expression of genes controlling the synthesis of various growth factors, including cytokines [5]. Considering the influence of cytokines on the human body, we can distinguish two major groups, one being proinflammatory mediators (which stimulate the cellular and humoral inflammatory response, lymphocyte proliferation, B cell production, activation and adhesion, neutrophil aggregation, production of acute-phase proteins in the liver, and the hypothalamic fever reaction. The most important of them are IL-2, IL-6, IL-8, IL-15, TNF- $\alpha$, and INF- $\gamma$. The other group has an antiinflammatory effect (inhibiting the production of pro-inflammatory mediators and stimulating the production of soluble cytokine receptors, for example, IL-10) [6].

The aim of this study was to analyze pro- and anti-inflammatory cytokine concentrations in the saliva and serum of patients with acute lymphoblastic leukemia undergoing remission maintenance therapy or after therapy cessation and comparing the results with the incidence of oral mucosal lesions.

\section{Material and methods}

\section{Patients and clinical assessment}

The study included 84 patients divided into two groups - study and control. There were 44 children in the study group. They were all treated for acute lymphoblastic leukemia according to the ALL-IC BFM 2002 program in the past at the Department of Pediatric Hematology and Oncology, Medical University of Lublin, with strict adherence to the appropriate protocols.

Forty children selected using an analogous method with regard to age and sex were included in the control group. They reported for routine dental check-ups without any recognized systemic chronic diseases.

The study group was then divided into two subgroups - the first one (A), which included patients who at the moment of the study were still receiving $A L L$ remission maintenance therapy, and the second (B), in which children were in the first year after the treatment cessation. The treatment period in group A was counted in weeks from the start of the maintenance phase and the median at the time of the study was 47 weeks. The age of children in all groups did not differ significantly, but the children in study groups had a significantly lower body weight compared to the control group. In addition to that, children during remission maintenance therapy had significantly lower body weight than those after the end of treatment. Details on age structure, height and body mass of both study and control groups are included in Table 1.

To assist a clinical assessment, a patient study card had been prepared by the authors. It featured personal data, a questionnaire regarding subjective complaints, dental chart, oral lesions chart, and a Visual Analogue Scale (VAS) describing the subjective intensity of illness-related discomfort, which provides an easy and reproducible way to assess subjective complaints originating from the oral cavity. This scale comprises different face images starting with a smiling one (no pain) to which a value of zero had been assigned and an unhappy grimace (maximum pain) on the opposite end, with an assigned value of 10 . The intermediate picture included faces with an increasing grimace with numerical values ranging from one up to nine. A separate questionnaire and a chart served to describe any changes in the mucosa such as epithelium disorders, ulcerations or mucositis. Dental examinations were performed with basic diagnostic kits in artificial light.

\section{Serum and saliva samples collection}

During a routine check-up visit at the hematology clinic, blood and saliva samples were taken from each patient from the study group, followed by oral cavity examination. The control group was examined in the same way in the Oral Medicine Department, Medical University of Lublin.

Blood samples of $3.5 \mathrm{ml}$ each were collected using serum separator tubes (SST). Samples were allowed to clot for 30 minutes at room temperature before centrifugation for 15 minutes at $1000 \times \mathrm{g}$ at room temperature. Serum was removed and stored frozen at $\leq-20^{\circ} \mathrm{C}$ in Eppendorf tubes until assayed.

Secretion of saliva was stimulated by chewing on unflavored paraffin pieces. $2 \mathrm{ml}$ samples were collected into a sterile container. Saliva samples visibly contaminated with blood were discarded and recollected. Samples were refrigerated immediately after collection and centrifuged for 10 minutes at $1000 \times \mathrm{g}$ at $4^{\circ} \mathrm{C}$. Supernatants were stored frozen at $\leq-20^{\circ} \mathrm{C}$ in the Eppendorf tubes until assayed.

\section{Cytokines levels ELISA assay}

Serum and saliva concentrations of IL-2, IL-6, IL-10, TNF- $\alpha$ and INF- $\gamma$ were measured using the enzyme-linked

Table 1. Comparison between study and control groups

\begin{tabular}{lcccc}
\hline Feature & Test group A & Test group B & Control group & $p$ \\
\hline Number of children & 21 & 23 & 40 & \\
$\quad$ Male, $n(\%)$ & $10(48)$ & $13(56)$ & $21(52)$ & 0.8 \\
$\quad$ Female, $n(\%)$ & $11(52)$ & $10(44)$ & $19(48)$ & \\
Age (years), median (range) & $5.5(4-18)$ & $8(5-17)$ & $8(4-15)$ & 0.1 \\
Body weight (kg), median (range) & $23(15-97)$ & $28.5(20-67)$ & $36(19-50)$ & 0.001 \\
Height (cm), median (range) & $122(102-175)$ & $125(100-168)$ & $135.5(99-155)$ & 0.1
\end{tabular}


Table 2. Cytokine kits specifications

$\begin{array}{lccc}\text { Cytokine } & \text { Cat. No. } & \text { Assay range } & \text { Sensitivity } \\ \text { IFN-7 } & \text { DIF50 } & 15.6-1000 \mathrm{pg} / \mathrm{ml} & 8 \mathrm{pg} / \mathrm{ml} \\ \text { TNF- } \alpha & \text { HSTA00E } & 0.2-10 \mathrm{pg} / \mathrm{ml} & 0.049 \mathrm{pg} / \mathrm{ml} \\ \text { IL-2 } & \text { D2050 } & 31.2-2000 \mathrm{pg} / \mathrm{ml} & 7 \mathrm{pg} / \mathrm{ml} \\ \text { IL-6 } & \text { D6050 } & 3.1-300 \mathrm{pg} / \mathrm{ml} & 0.7 \mathrm{pg} / \mathrm{ml} \\ \text { IL-10 } & \text { D1000B } & 7.8-500 \mathrm{pg} / \mathrm{ml} & 3.9 \mathrm{pg} / \mathrm{ml}\end{array}$

immunosorbent assay (ELISA) method using Quantikine sets produced by R\&D Systems (USA) (Table 2).

The authors followed the attached manufacturer's instructions and recommendations. Standards, controls and samples were assayed in duplicate and duplicate readings were averaged. The optical density was determined by a VICTOR3 microplate reader (Perkin Elmer, USA). A standard five-parameter logistic (5-PL) curve fit was generated using computer software (WorkOut 2.0). The concentration of each cytokine was read from the standard curve.

\section{Statistical analysis}

Obtained results were subjected to statistical analysis using the program STATISTICA 13. In the initial stage, the Kruskal-Wallis nonparametric test was used for all three groups of patients, followed by the Mann-Whitney $U$ test to assess possible differences between particular groups; differences were considered statistically significant if $p<0.05$.

Permission of the Ethical Committee of the Medical University of Lublin was obtained for conducting this research.

\section{Results}

A statistically significant difference in the concentrations of the pro-inflammatory cytokine TNF- $\alpha$ was re-

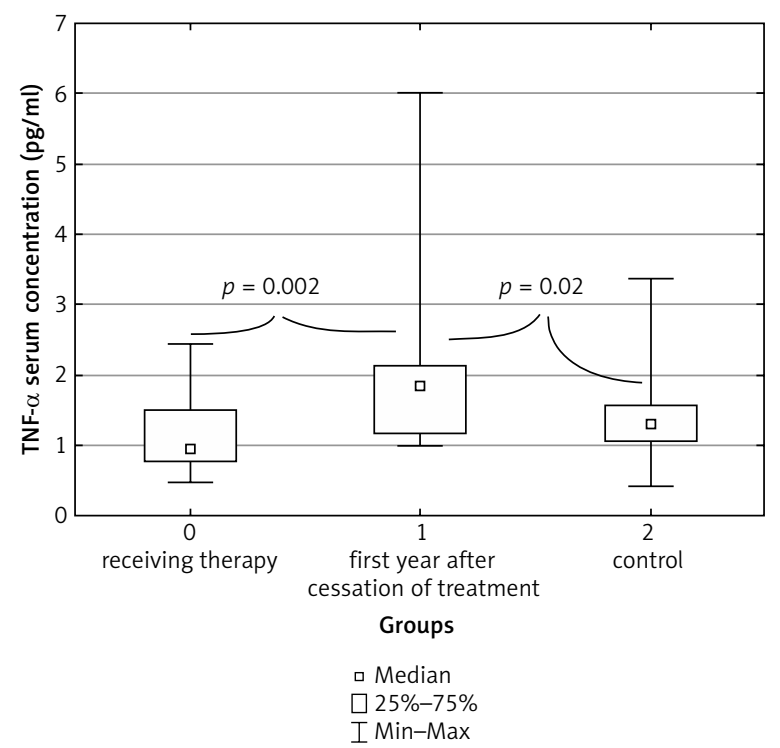

Fig. 1. Serum concentration of TNF- $\alpha$ in analyzed groups vealed in the serum of patients in all three groups tested $(p=0.004)$. The highest serum concentration of this cytokine was found in study group B - children who were in their first year after the end of treatment. The median for this group was $1.862 \mathrm{pg} / \mathrm{ml}(0.988-6.002 \mathrm{pg} / \mathrm{ml})$ and was significantly higher than both the median for the control group results $-1.284 \mathrm{pg} / \mathrm{ml}(0.420-3.378 \mathrm{pg} / \mathrm{ml})$, and median results of children still in the remission phase -0.944 pg/ml (0.489-2.445 pg/ml) (Fig. 1).

A similar result was obtained for the tested salivary samples, in which the highest concentration of TNF- $\alpha$ was observed in the group of children after the end of treatment, with a median of $0.457 \mathrm{pg} / \mathrm{ml}(0.207-1.022 \mathrm{pg} / \mathrm{ml})$. It was significantly higher than the median result of children from the control group: $0.363 \mathrm{pg} / \mathrm{ml}(0.017-1.462 \mathrm{pg} /$ ml) (Fig. 2).

For anti-inflammatory agents, the study revealed statistically significant differences between groups in IL-10 concentrations both in serum $(p=0.007)$ and in saliva ( $p=0.001)$. For serum, the highest concentration of IL-10 was recorded in children in the first year after the end of remission maintenance treatment. The median result was $26.06 \mathrm{pg} / \mathrm{ml}(13.50-131 \mathrm{pg} / \mathrm{ml})$, and was significantly higher than the median result of the control group, $15.9 \mathrm{pg} / \mathrm{ml}$ (0.435-98.36 pg/ml) (Fig. 3).

In saliva however, the highest IL-10 concentration was obtained in the control group (median $19.10 \mathrm{pg} / \mathrm{ml}$, range

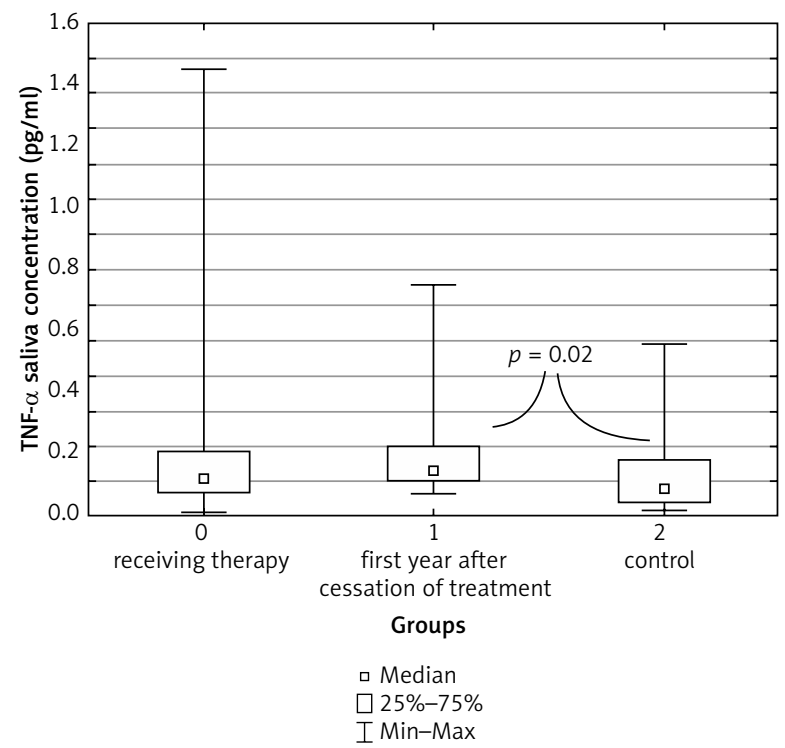

Fig. 2. Saliva concentration of TNF- $\alpha$ in analyzed groups 


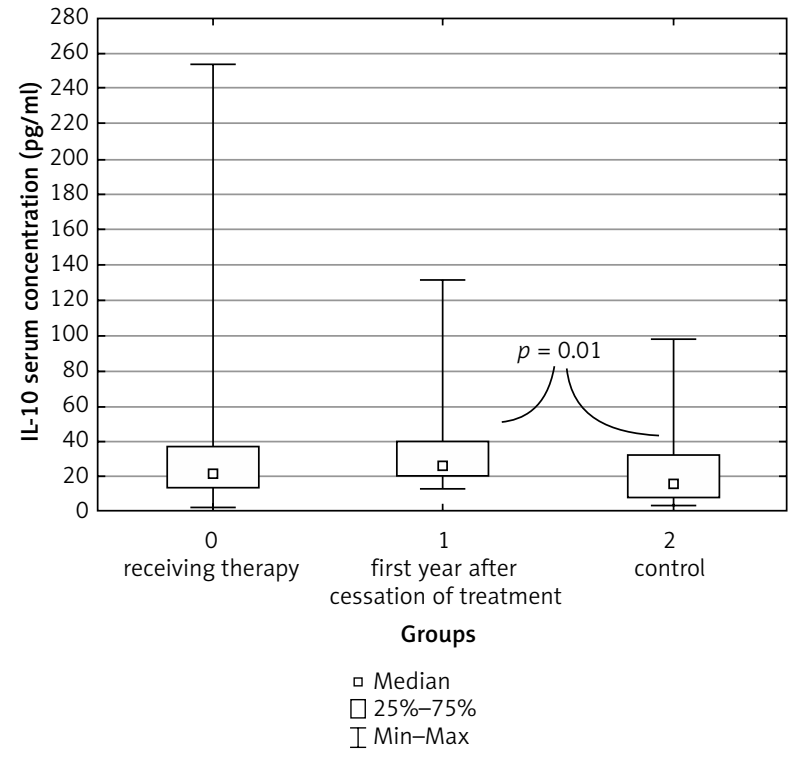

Fig. 3. Serum concentration of IL-10 in analyzed groups

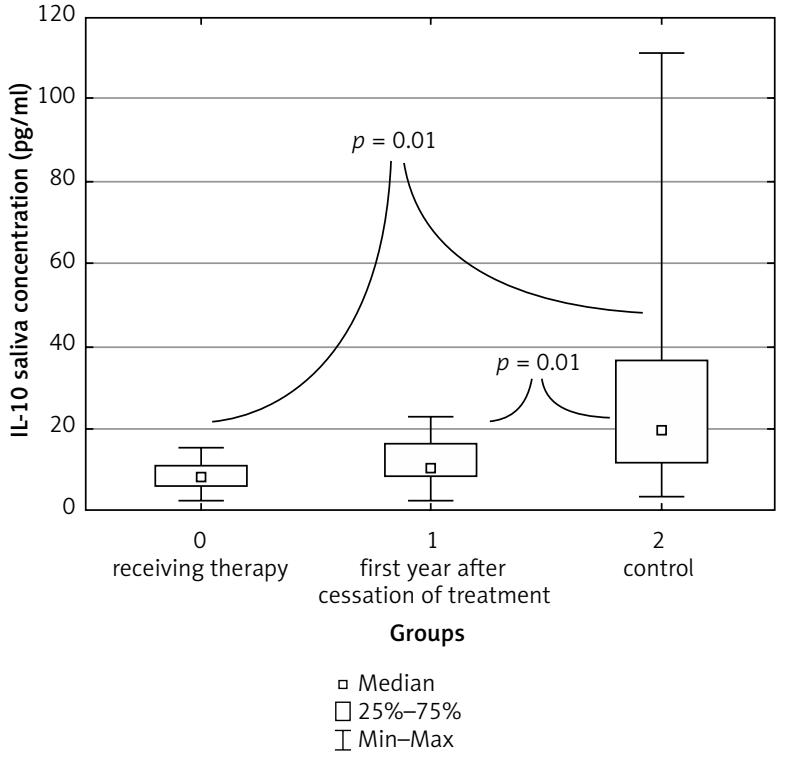

Fig. 4. Saliva concentration of IL-10 in analyzed groups

Table 3. Other cytokines concentrations

\begin{tabular}{lccc} 
Cytokine & \multicolumn{3}{c}{ Group } \\
\cline { 2 - 4 } & $\begin{array}{c}\text { Patients receiving treatment } \\
\text { Median (min-max) }\end{array}$ & $\begin{array}{c}\text { Patients in the first year after } \\
\text { cessation of the treatment } \\
\text { Median (min-max) }\end{array}$ & $\begin{array}{c}\text { Control } \\
\text { Median (min-max) }\end{array}$ \\
\hline INF- $\gamma$ saliva $(\mathrm{pg} / \mathrm{ml})$ & $2.465(0.791-10.595)$ & $3.762(0.889-6.207)$ & $3.297(0.105-12.09)$ \\
\hline INF- $\gamma$ serum $(\mathrm{pg} / \mathrm{ml})$ & $7.252(0.081-17.872)$ & $4.218(0.336-26.846)$ & $3.298(0.025-29.666)$ \\
IL-2 saliva $(\mathrm{pg} / \mathrm{ml})$ & $4.279(0.001-7.292)$ & $1.592(0.035-6.027)$ & $2.252(0.038-10.073)$ \\
IL-2 serum $(\mathrm{pg} / \mathrm{ml})$ & $0.974(0.0246-4.139)$ & $1.888(0.048-6.337)$ & $2.190(0.064-16.409)$ \\
IL-6 saliva $(\mathrm{pg} / \mathrm{ml})$ & $5.843(0.272-130.353)$ & $5.204(0.317-50.604)$ & $4.228(0.201-81.875)$ \\
\hline IL-6 serum $(\mathrm{pg} / \mathrm{ml})$ & $1.711(0.054-3.448)$ & $1.389(0.418-30.066)$ & $2.002(0.194-4.595)$
\end{tabular}

3.443-111 pg/ml). It was significantly higher than the concentration of IL-10 in the saliva of children in the remission maintenance phase (median $8.304 \mathrm{pg} / \mathrm{ml}$, range $2.456 \mathrm{pg}$ / $\mathrm{ml}-15.25 \mathrm{pg} / \mathrm{ml}$ ) and in the saliva of children who were in their first year after the therapy cessation (median 10.23 $\mathrm{pg} / \mathrm{ml}$, range $2.532 \mathrm{pg} / \mathrm{ml}-22.71 \mathrm{pg} / \mathrm{ml}$ ) (Fig. 4).

For the other cytokines examined, statistical analysis did not show significant differences between the groups. (Table 3).

The authors reviewed the patients' answers concerning subjective complaints regarding the oral cavity, but found no statistically significant differences between groups. On the other hand, the $p$ value of 0.08 indicates the tendency of children from the control group to report slightly stronger complaints. The highest median of the VAS index was observed in the control group, in which it was equal to 1 (range 0-6), while the lowest was for both the maintenance therapy group (median 0 , range $0-7$ ) and the post-treatment group (median 0, 0-7). The comparison of the average VAS index results is presented in the graph (Fig. 5).
The authors observed mucosal lesions in all three groups of the examined children. However, they were more frequent in the ALL children (19 cases) than in the control group (2 cases). In addition, there was a noticeable difference between the study groups $A$ and $B$, indicating a higher incidence of mucosal lesions in children in the maintenance phase of ALL remission. In the control group, only two cases of epithelial lesions were observed, both showing features of a benign bite line, etiology of which is associated with chronic mechanical injury and chewing of the buccal mucous membrane with the patient's own dentition. Among children undergoing remission maintenance treatment 13 cases of epithelial disorders were observed. Patients in their first year after therapy cessation showed 6 cases of such disorders. In contrast to cases from the control group, lesions revealed in both study groups A and $B$ were of atrophic origin and manifested by lingual filamentous warts smoothing and pale turbidity within the buccal mucous membrane. Location of those lesions ruled out possible traumatic etiology. Between serum TNF- $\alpha$ levels and the incidence of oral lesions in children receiv- 
ing remission maintenance therapy, the authors revealed a negative correlation with a significance level of $p=0.04$.

\section{Discussion}

The extremely wide spectrum of cytokines' activity in most aspects of human body functioning, and their critical role in the proper functioning of the immune system, suggest a relationship between their concentrations in the blood and saliva of patients and their health and morbidity risk and may be a prognostic factor in further treatment. Many authors have conducted studies in which the possible relationship between pro- and anti-inflammatory cytokines and the course of the disease was assessed. Horacek et al. compared the concentration of 17 cytokines in the peripheral blood of patients with a fresh diagnosis of ALL and AML. The study revealed significantly higher levels of proinflammatory IL-2 and anti-inflammatory IL-4, compared to the control group [7]. In our study, similar interleukin concentrations did not differ significantly from the control group. It may result from patients undergoing different phases of treatment at the time of examination.

Another study indicated a relationship between anti-inflammatory IL-10 deficit in neonates and increased risk of developing ALL in the future [8]. Our own results for IL-10 concentration in saliva are highest in the control group, the lowest on the other hand in children who fell ill and at the time of the examination received maintenance therapy. A few studies indicate an increased level of IL-10 in the blood of cancer patients and an increase in the rate of proliferation and tumor growth being correlated with higher concentration of this cytokine $[9,10]$. In studies carried out by the authors of this article, the highest concentration of IL-10 in serum was found in patients in the first year after the therapy cessation, which suggests prolonged high activity of the immune system in response to the disease. The largest range of results obtained for children receiving maintenance therapy, reaching up to approx. $250 \mathrm{pg} / \mathrm{ml}$, seems to be significant. Abeer Abd Elmoneim et al. in their studies on IL-10 and IL-12 concentrations in children with various neoplastic diseases, including hematologic ones, found increased levels of IL-10 in response to cancer compared to the control group [11]. Higher concentrations of IL-10 and IL-12 were also associated with worse prognosis according to these authors.

Analyzing the concentration of pro- and anti-inflammatory cytokines in blood after ALL chemotherapy, Mazur et al. did not find significant differences for the anti-inflammatory IL-10 compared to the control group. However, for pro-inflammatory cytokines, their study revealed a significant increase in the levels of $\mathrm{IL}-2$ and IL-8 and TNF- $\alpha$ [12]. This suggests dominance of inflammatory processes in the initial stages of treatment. Similar conclusions were reached by Prymak et al., noting significantly higher levels of TNF- $\alpha$ in the blood of ALL patients linked to an increased immune response to the disease [13]. In the study conducted by the authors, the highest concentration of TNF- $\alpha$ was obtained in the saliva and serum of children in the first year after completion of maintenance therapy in comparison to the control group. It may

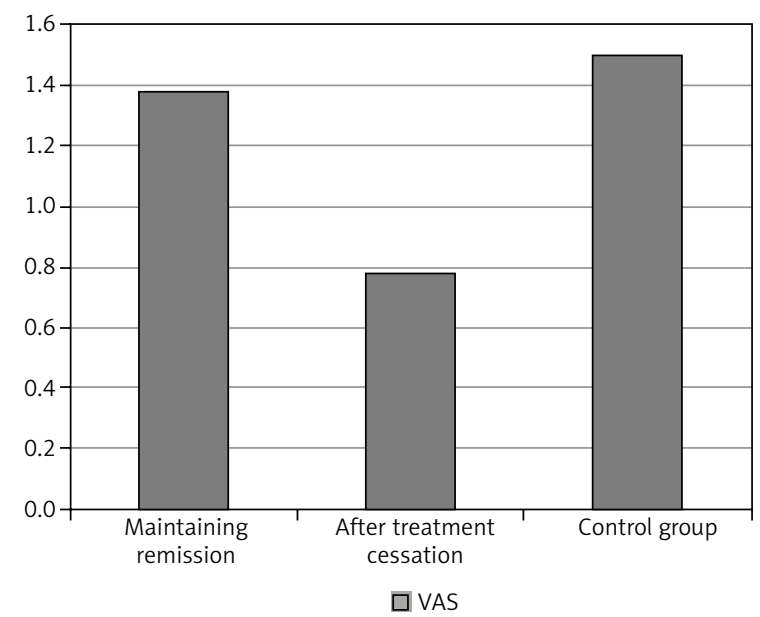

Fig. 5. Average subjecitve complaines according to Visual Analogue Scale (VAS) in analyzed groups

indicate that the immune system is still highly involved in combating the disease and its effects.

The authors of this article revealed a negative correlation between the prevalence of lesions on the oral mucosa and serum TNF- $\alpha$ concentration in children receiving maintenance treatment. These results contrast with the results of research on children during chemotherapy, in which in the first days after drug administration an elevated concentration of IL- 6 and TNF- $\alpha$ was found in the developing acute phase of mucositis [14]. The study conducted by Pels [15] showed a higher incidence of gingivitis in children receiving chemotherapy and an increase in the level of IL-2 in their saliva compared to the control group. The study indicates mucosal micro-traumas developing after administration of cytostatics as a cause of increased IL-2 release to the saliva and development of mucositis. The differences in our study and results obtained by other authors may be caused by extremely different oral hygiene in individual patients, because the relationship between local inflammatory diseases of dental hard tissue (caries) and the concentration of proinflammatory cytokines such as TNF- $\alpha$ and IL- 6 and IL- 8 in saliva has been proven [16]. It should also be taken into account that the patients from the Pels study were undergoing induction and consolidation chemotherapy, while our patients were in the maintenance phase when the treatment was significantly less intense.

The relationship between the strong mucotoxicity of drugs used in the initial phases of treatment and the oral health of patients has been confirmed in numerous studies. Valera et al. lists mucositis, opportunistic infections, ulcers, dry mouth and dental caries as prevalent and severe complications of acute-phase chemotherapy [17]. The oral health deteriorates significantly at the beginning of an anti-cancer treatment [18]. Changes in the mucosa observed by us in children in the maintenance phase and after its completion were disorders of keratinization, which arose later due to impaired healing of primary ulcerations and mucositis [19]. These lesions were more common in children treated for ALL compared to the control group. Oral discomfort that accompanies children at the beginning of 
treatment is strong, followed by very high stress associated with hospitalization, fear for their own lives and frequent visits to the physician. The oral cavity-related quality of life in the maintenance phase and after its completion is mainly influenced by the physical limitations associated with the side effect of taken medication - dryness, change of taste, and episodic pain during eating [20]. In patients undergoing this study however, study group patients did not report significantly worse life quality. The authors presume that the possible and probable reason for this is the success in the fight against cancer, which pushed the unpleasantness associated with the treatment itself into the background. This effect seems to be stronger the less time has passed since remission was obtained. It is indicated by the slightly higher mean value of VAS in children in the maintenance phase compared to those who completed the treatment. Surprisingly, the VAS index mean value was the highest in the control group. According to the authors, this is due to the lack of comparison to the traumatic experience of chemotherapy for young patients.

\section{Conclusions}

Acute lymphoblastic leukemia is a severe systemic disease that strongly interferes with the functioning of the immune system, which is reflected in the activity of anti and pro-inflammatory mediators. The disease and its treatment have a strong negative impact on the patient's organs, including the oral cavity, contributing to a significant deterioration in the quality of life. Strong complaints at the beginning of treatment, difficulties in maintaining proper oral hygiene during the therapy and the presence of long-term lesions in the oral cavity after the end of treatment lead to the conclusion that a pediatric dentist should be actively involved in multi-specialist care not only in the acute phase of treatment but also for a long time after it has finished.

The authors declare no conflict of interest.

\section{References}

1. Kowalczyk JR. Ostra białaczka limfoblastyczna. In: Onkologia Dziecięca, Chybicka A, Sawicz-Birkowska K (eds.). PZWL, Warszawa 2008; 205-219.

2. Biondi A, Cimino G, Pieters R, Pui CH. Biological and therapeutic aspects of infant leukemia. Blood 2000; 96: 24-33.

3. Stary J, Zimmermann M. Intensive chemotherapy for childhood acute lymphoblastic leukemia: results of the randomized intercontinental trial ALL IC-BFM 2002. J Clin Oncol 2014; 32: 174-184.

4. Dyszkiewicz M, Shaw H. Ocena stanu błony śluzowej jamy ustnej u pacjentów leczonych radio- i chemioterapią. Dent Med Probl 2009; 46: 89-93.

5. Vincent JL. The immune response in critical illness: excessive, inadequate or dysregulated. In: The Immune Response in Critical IIIness, Marshall JC, Cohen J (eds.). Springer-Verlag, New York 1999.

6. Karpel E. The place of systemic inflammatory response mediators in intensive care. Anestezjologia Intensywna Terapia 2001; 3: 181190.

7. Horacek JM, Kupsa T, Vasatova M, Jebavy L, Zak P. Serum cytokine and adhesion molecule profile differs in newly diagnosed acute myeloid and lymphoblastic leukemia. Biomed Pap Med Fac Univ Palacky Olomuc Chech Repub 2015; 159: 299-301.
8. Chang JS, Zhou M, Buffler PA, Chokkalingam AP, Metayer C, Wiemels JL. Profound deficit of IL 10 at birth In children who develop childhood acute lymphoblastic leukemia. Cancer Epidemiol Biomarkers Prev 2011; 20: 1736-1740.

9. Sabat R, Asadullah K. Interleukin-10 in cancer immunity. In: Cancer immune therapy: current and future strategies, Stuhler G, Walden P (eds.). Wiley VCH, Germany 2002.

10. Chan IH, Wu V, McCauley S, Grimm EA, Mumm JB. IL-10: expand ing the Immune Oncology Horizon. Receptors Clin Investig 2015; 2: 1041.

11. Elmoneim AA, Sabr MS, Alsuhaymi AS, Alkurdestani W, Alhawsawy Z, Zolaly M. Interleukins IL-10, IL-12, IL-10/IL-12 ratio and IL-23 serum levels In different paediatric malignacies. Biomed Res 2017; 28: issue 7.

12. Mazur B, Mertas A, Sońta-Jakimczyk D, Szczepański T, Janik-Moszant A. Concentration of IL-2, IL-6, IL-8, IL-10 and TNF $\alpha$ in children with acute lymphoblastic leukemia after cessation of chemotherapy. Hematol Oncol 2004; 22: 27-34.

13. Prymak SV, Matlan VL, Barilka VA, Shalay OO, Loginsky VE. Tumor necrosis factor in acute leukemia patients. Oncol 2015; 17: 17-21.

14. Morales-Rojas T, Viera N, Moron-Medina A, Alvarez CJ, Alvarez A. Proinflammatory cytokines during the initial chase of oral mucositis in patients with acute lymphoblastic leukemia. Int J Paediatr Dent 2012; 22: 191-196.

15. Pels E. Comparison of saliva interleukin-2 concentration to the conditio of gums in children with acute lymphoblastic leukemia Turing anti-tumour treatment. Cancer Chemother Pharmacol 2015; 76: 205-210.

16. Gornowicz A, Bielawska A, Bielawski K, Grabowska SZ, Wójcicka A, Zalewska M, Maciorkowska E. Pro-inflammatory cytokines in saliva of adolescents with dental Karies disease. Ann Agric Environ Med 2012; 19: 711-716.

17. Valéra MC, Noirrit-Esclassan E, Pasquet M, Vaysse F. Oral complications and dental care in children with acute lymphoblastic leukaemia. J Oral Pathol Med 2015; 44: 483-489.

18. Dholam KP, Gurav S, Dugad J, Banavli S. Correlation of oral health of children with acute leukemia during the induction phase. Indian J Med Paediatr Oncol 2014; 35: 36-39.

19. Pels EJ. Oral mucositis and saliva IgA, IgG and IgM concentration during anti-tumor treatment in children suffering from acute lymphoblastic leukemia. Adv Clin Exp Med 2017; 26: 1351-1358.

20. Jung SH, Ryu JI, Tsakos G, Sheiham A. A Korean version of the Oral Impacts on Daily Performances scale in elderly population: validity, reliability and prevalence. Health Qual Life Outcomes 2008; 27: 17 .

\section{Address for correspondence}

\section{Przemysław M. Krzaczek}

Department of Oral Medicine

Medical University of Lublin

58 Lubartowska St.

20-094 Lublin, Poland

e-mail: krzaczek.p@gmail.com

Submitted: 28.01.2019

Accepted: 2.04.2019 